\title{
OS CONCEITOS DIVISORES DO ESPAÇO: REFLEXÕES EM TORNO DE UMA INTERAÇÃO ENTRE A HISTÓRIA E A GEOGRAFIA
}

\author{
SPACE DIVIDING CONCEPTS: REFLECTIONS AROUND AN \\ INTERACTION BETWEEN HISTORY AND GEOGRAPHY
}

\author{
José D'Assunção Barros ${ }^{1}$
}

\section{RESUMO}

Este artigo busca examinar, no âmbito de interação entre a História e a Geografia como campos de saber, os principais conceitos que se referem à divisão do espaço no seio das ciências humanas. Respectivamente, são discutidos os conceitos de região, área, zona e território, evocando-se alguns autores provenientes da Geografia que podem ser particularmente úteis para os estudiosos de História. Uma exemplificação sobre o padrão de divisão do espaço diante de um problema em particular é trazida por uma análise específica da obra A Geografia da Fome, de Josué de Castro.

\section{PALAVRAS-CHAVE:}

Espaço, Região, Área, Território, Conceitos geográficos.

\begin{abstract}
This article attempts, within the context of interaction between History and Geography as fields of knowledge, the main concepts that refer to the division of space within the human sciences. Respectively, the article develops an examen of the concepts of region, area, zone, and territory, evoking some authors from Geography that may be particularly useful for History researches. An example of the pattern of division of space in the face of a specific problem is brought by an analysis of Josué de Castro's The Geography of Hunger.
\end{abstract}

\section{KEYWORDS:}

Space, Region, Area, Territory, Geographical Concepts.

\footnotetext{
${ }^{1}$ Professor Associado nos cursos de graduação e pós-graduação em História da Universidade Federal Rural do Rio de Janeiro (UFRRJ), e Professor Permanente do Curso de Pós-Graduação em História Comparada da Universidade Federal do Rio de Janeiro (UFRJ). Doutor em História pela Universidade Federal Fluminense. Autor de 30 livros nas áreas de Teoria da História, Interdisciplinaridades e História da Arte (Artes Visuais, Cinema, Música, Literatura). Coordena o LAPETHI (Laboratório de Pesquisas em Teoria da História e Interdisciplinaridades
} 


\section{Os divisores do Espaço, na História e na Geografia}

"Regiões são subdivisões do espaço: do espaço total, do espaço nacional, e mesmo do espaço local, porque as cidades maiores também são passíveis de regionalização" (SANTOS, 2013, p.94).

Tradicionalmente imaginada como o campo de saber que atenta para o tempo e para as relações temporais envolvidas na vida humana, em particular na vida dos homens em sociedade, a História, por outro lado, nunca pôde prescindir de uma atenção concomitante à instância do Espaço. Os historiadores sempre precisaram lidar, para estabelecer seus recortes de pesquisa e os limites das realidades a serem observadas na história, com os diversos conceitos que operacionalizam a divisão do espaço em unidades ou conjuntos inteligíveis. O debate com a Geografia, neste aspecto em particular, sempre foi vital para a História. Neste artigo, pretendemos discutir os conceitos que permeiam, entre a História e a Geografia, a discussão sobre o espaço.

Entre os conceitos que operacionalizam a divisão do espaço, talvez o mais importante para a História seja o de "região". É, ao menos, o primeiro conceito a ser discutido, pois dele decorrem outros. $\mathrm{O}$ aspecto inicial a ser compreendido, por evidente que isso soe, é o de que a região é uma "subdivisão do espaço". É mais do que isso, certamente, mas esta é como que a nota característica fundamental do acorde conceitual de "Região". Por sobre a ideia de que a região é uma 'subdivisão do espaço' (e outros conceitos também partem desta ideia, como os de "área", "zona", e tantos outros), é que podemos iniciar um entendimento mais adequado acerca das diversas possibilidades de sentido que se agregam ou se correlacionam ao conceito de região.

Conforme ressalta o geógrafo Milton Santos (1926-2001) na passagem que destacamos em epígrafe, a princípio podemos pensar em regiões como divisões decorrentes de diversos tipos de totalidades. Se pensarmos no planeta como totalidade no planeta político, por exemplo, com seus diversos países e relações de vizinhança ou de distanciamento físico de uns em relação aos outros, mas também nas proximidades geradas pelos distintos sistemas de alianças entre as nações - a região surge como categoria conveniente para os estudos de Relações Internacionais e para o vocabulário corrente da História Global. Pode-se dizer, em referência ao Atlântico Sul, que o Brasil 
estabelece relações de cooperação deste ou daquele tipo com "os países da região". Países que partilham fronteiras podem ser agregados em regiões dentro desta totalidade maior que é o planeta, ou dentro dos continentes.

À parte esta primeira leitura das regiões como subdivisões que podem ser estabelecidas no espaço planetário ou continental - e deixando por ora de discutir a possibilidade de pensar regiões como subdivisões possíveis no interior de grandes cidades - a noção mais corrente de região, entre os historiadores, é a que se associa a subdivisões dos espaços nacionais. A região como uma categoria através da qual se pode pensar uma diferenciação interna do país - entendendo este último como uma totalidade - consolidouse com o desenvolvimento de uma modalidade historiográfica específica, sobre a qual discorreremos em maior profundidade mais adiante: a História Regional.

\section{Região: elementos que conformam o conceito}

Por ora, passemos às outras notas que devem constituir o acorde conceitual de região, para além desta ideia matriz de que a região é uma divisão do espaço. Do ponto de vista estritamente geográfico, se uma região é uma unidade definível no espaço, o que permite pensá-la precisamente como 'unidade' (segunda nota característica deste conceito) é precisamente a ideia de que se pode enxergar nela certa 'identidade'. De fato, uma região se caracteriza por uma relativa homogeneidade interna com relação a certos critérios. Temos aqui a “di-visão” à qual se refere Bourdieu (BOURDIEU, 1989, p.113): com a noção de região, pode-se "ver" o espaço cindido. Ou, antes, pode-se ver de maneira cindida o espaço, pois sempre, e em todos os casos, a região não é mais do que uma construção da mente que destaca certos aspectos em uma área, e que a compara com outras.

Uma área unida por certos elementos que lhe trazem alguma homogeneidade, ao menos a partir de certa perspectiva, separa-se de outras regiões, ou de outras porções do espaço que apresentam características diferentes. Essa operação mínima permite que comecemos a pensar o espaço em termos de regiões, embora ainda sejam necessários outros fatores para que estejamos mais propriamente diante de uma região, e não de outros tipos de divisões que podem cortar o espaço. Até aqui, nosso conceito de região pode ser 
representado com um acorde em formação, o qual se expressa através das seguintes notas características:
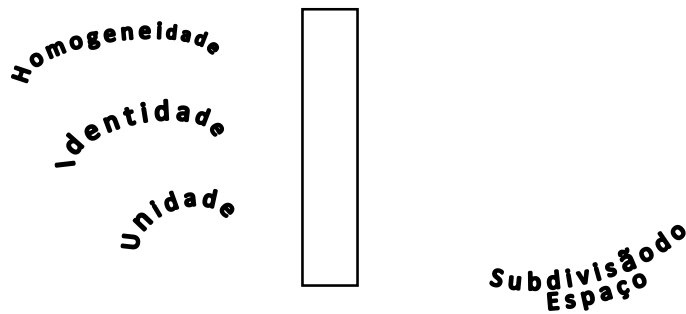

Região

Será conveniente, em seguida, atentarmos para o fato de que a homogeneidade interna de uma região, sempre relativamente a algum critério (uma função econômica que atravessa aquela porção do espaço através de uma prática agrícola ou industrial predominante, uma certa paisagem geográfica mais recorrente, a presença de características físicas ou populacionais bem definidas, ou quaisquer outras), não implica necessariamente na inexistência de diversidade interna no espaço que pretendemos compreender como uma região. Ao lado da cisão entre um 'dentro' e um 'fora', uma região pode apresentar até mesmo muita diversidade interna. Ela pode inclusive suscitar novas subdivisões no espaço, e se partir em áreas distintas, sem que isso prejudique a possibilidade de que ela continue a ser entendida como uma unidade.

O principal é que, se pretendemos falar mais seriamente de uma região, tenhamos em vista algo que unifica este espaço, que permita confrontá-lo a outros, que lhe traga certa singularidade no interior da totalidade à qual a região se refere (planeta, continente, país). Pode ser que aquilo que traz identidade à região seja um determinado padrão visual, físico, econômico, cultural, certo universo eleitoral ou jurisdição afeita a este ou àquele poder, ou ainda, como é muito comum, determinada função que a região exerce no seio de um sistema maior.

Os elementos que trazem 'identidade' e 'unidade' à região podem variar - e serão sempre redefinidos de acordo com os critérios escolhidos por aquele que pretende operacionalizar o conceito - mas eles precisam existir. Esses elementos constituem os aspectos a partir dos quais se pode efetivamente discorrer sobre porque o espaço foi dividido de uma maneira, e não de outra. Vejamos, em seguida, uma representação mais complexa do acorde conceitual de "região": 


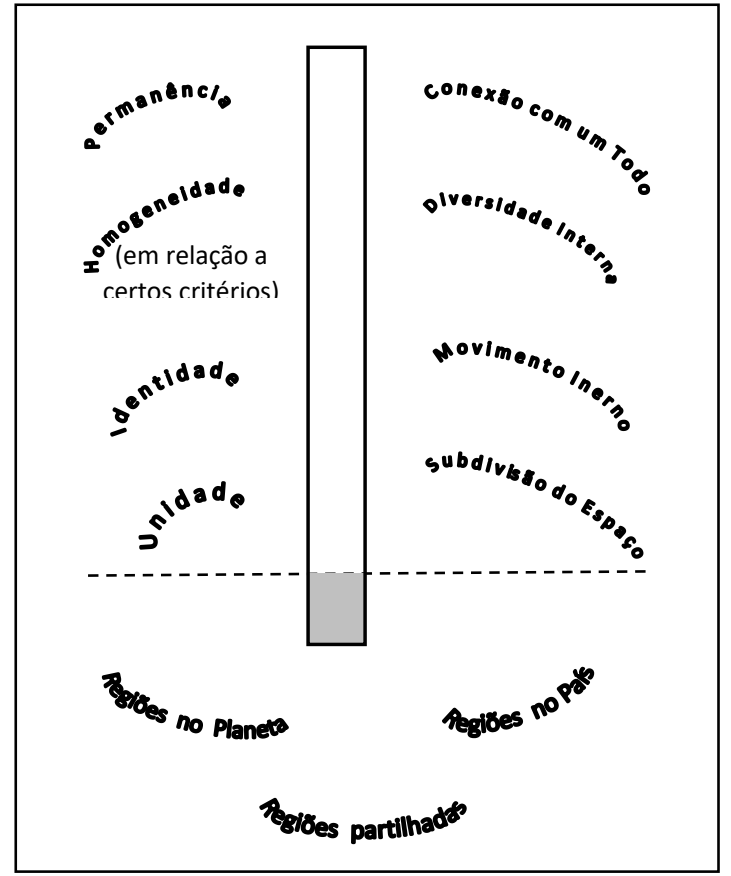

O esquema acima apresenta as principais notas características que habitualmente estão envolvidas na constituição do conceito de "região". Acima da linha pontilhada, encontram-se as notas que devem interagir de modo a constituir este conceito (correspondem, mais propriamente, à chamada 'compreensão' do conceito). Abaixo da linha pontilhada estão os casos aos quais pode se referir um tal conceito de região, uma vez que ele seja definido a partir das características acima propostas (esta é a chamada 'extensão' do conceito).

Vamos nos concentrar, inicialmente, nas notas características do conceito de região. Temos aqui fatores diversos que interagem, e que devem acontecer todos de uma única vez para que tenhamos, de fato, uma região. Uma 'subdivisão no espaço' - e, no entanto, uma 'unidade' dotada de 'identidade' e de 'homogeneidade' com relação a algum critério (uma função que a caracteriza, certas características físicas ou humanas, entre outros possíveis). Não obstante isso, a região pode perfeitamente comportar uma eventual 'diversidade interna', susceptível mesmo de promover novas divisões no espaço (áreas internas à região).

Uma 'permanência' considerável no espaço e no tempo é o que permitirá que a região seja de fato vista como uma área bem definida, senão pelos seus próprios contemporâneos e habitantes, ao menos pelos pesquisadores que a estudarem. Por vezes, 
aliás, são os próprios estudiosos aqueles que assumem a tarefa de definir os limites e contornos de uma região com referência a um problema científico qualquer. Com relação ao fator 'permanência', este não impede que a região apresente uma dinâmica interior, um movimento interno, ciclos e transformações divergentes. No quadro, sintetizei através da expressão 'movimento interno' todas essas possibilidades de dinâmica e transformações que podem se dar no interior de uma região. Por fim, salienta-se ainda, para qualquer região, uma 'conexão com um todo', que pode ser o planeta, o continente, o país, ou ainda outras totalidades a serem definidas.

O último aspecto nos leva a pensar em vários tipos de regiões que podem ser abordados a partir das notas características acima formuladas para este conceito. Já vimos que, considerando níveis de análise diversos, podemos delinear as regiões como subdivisões que recortam o espaço planetário ou continental, ou que recortam um espaço nacional. Podemos até mesmo pensar em regiões que são partilhadas por dois ou mais países, como é o caso da Região do Prata, a qual é compartilhada pelos países da parte meridional da América do Sul. A região Amazônica - definida por uma vasta bacia hidrográfica de sete milhões de quilômetros quadrados e pela floresta latifoliada que a recobre - adentra nove países da América do Sul, inclusive o Brasil.

As regiões globais, as regiões intranacionais, e as regiões internacionais, portanto, constituem os tipos de espaços que podem ser definidos como regiões. As regiões globais - aquela que são recortadas da totalidade planetária - podem se referir a grupos de países, ou então a grandes áreas que dizem respeito a aspectos geográficos diversos. Países vizinhos, em geral - por exemplo, os países que ficam em certa parte de um continente, ou ainda países vizinhos que pertençam a continentes diversificados, como no Oriente Médio - são frequentemente vistos como regiões pelas análises políticas e pela História Global. Países que partilham uma mesma porção do oceano - o Atlântico Sul ou o Atlântico Norte - também podem ser abordados como regiões inseridas na totalidade global. Critérios geográficos - um grande deserto, como o Saara, ou então a área abaixo dele, chamada de África Subsaariana - podem servir de base para o delineamento de uma região.

Outros exemplos são os recortes do planeta por regiões climáticas, ou pelo predomínio de certos tipos de vegetação. Há por exemplo uma "geografia da fome", a qual busca definir as regiões do planeta que condizem com os diversos níveis de nutrição 
e desnutrição. As regiões relativas a recortes no interior de países específicos tornaramse muito importantes para a historiografia. Os próprios governos e sistemas políticos de cada estado-nação, quando este possui um território que não seja muito pequeno (casos excepcionais), costumam dividir o país em regiões que funcionam como unidades políticas menores (estados, províncias, etc).

Mas os próprios cientistas sociais, em sua diversidade de pesquisas, podem delinear eles mesmos suas próprias regiões de referência, de acordo com critérios que veremos mais adiante. Neste artigo, o que nos está interessando são principalmente as regiões como construções dos historiadores, geógrafos, antropólogos, economistas e outros cientistas sociais. Pode ser que as regiões por eles consideradas ou por eles constituídas coincidam com áreas pré-definidas politicamente, dependendo do que está em estudo. Isto, porém, constitui apenas uma possibilidade entre muitas outras.

\section{A Região como problema}

Voltemos, entrementes, aos aspectos que podem ser pensados como notas características para o conceito de região. Dizíamos atrás que um dos fatores que permitem que pensemos em regiões é a sua homogeneidade (a homogeneidade do seu espaço), sempre com relação a um critério ou mais. Devemos acrescentar que os elementos internos que concedem uma identidade à região (e que só se tornam perceptíveis quando estabelecemos critérios que favoreçam a sua percepção) não são, desde sempre, necessariamente estáticos. Daí que a região também pode ter a sua identidade delimitada e definida com base na percepção certo padrão de interrelações dentro dos seus limites. Vale dizer, a região também pode ser entendida como um sistema de movimento interno.

Por outro lado, além de ser uma porção do espaço organizada de acordo com um determinado sistema ou identificada através de um padrão, a região quase sempre se insere ou pode se ver inserida, conforme já vimos, em um conjunto mais vasto. Esta noção mais completa de região - como unidade que apresenta uma lógica interna ou um padrão que a singulariza, e que ao mesmo tempo se mostra como unidade a ser inserida ou confrontada em contextos mais amplos - abrange possibilidades diversas. Conforme os critérios que sustentem nosso esforço de aproximação da realidade, surgem concomitantemente as várias alternativas de dividir o espaço em regiões mais definidas. 
Posso estabelecer critérios econômicos - relativos à produção, circulação ou consumo para definir uma região ou dividir uma espacialidade mais vasta em diversas regiões. Em contrapartida, posso preferir critérios culturais: considerar uma região linguística, ou um território sobre o qual são perceptíveis determinadas práticas culturais que o singularizam, certos modos de vida e padrões de comportamento nas pessoas que o habitam.

Ao Enfatizar aspectos da geografia física, posso me orientar por critérios geológicos - e estabelecer em um espaço mais vasto as divisões que se referem aos tipos de minerais e solos que predominam em uma área ou outra - ou posso ainda considerar zonas climáticas ou bacias hidrográficas. $\mathrm{O}$ que ocorre, em todos estes casos e muitos outros, é que a região - encarada como subdivisão do espaço - decorre sempre de certa definição do espaço, pois mesmo este também constitui um conceito a ser construído.

A Geografia, é de se esperar, privilegia certos critérios: habitualmente lança luz sobre aspectos que se relacionam com a materialidade física - atmosférica, inorgânica ou orgânica - e pode ou não relacionar estes aspectos a outros de ordem cultural e histórica (como é o caso, de modo geral, da Geografia Humana). De um modo ou de outro, é importante se ter em vista que mesmo os critérios propostos como "naturais", com vistas a delinear regiões, comportam decisões subjetivas. De resto, cumpre notar que as diferentes propostas de dividir o espaço em regiões, valendo-se cada qual dos seus próprios critérios ou patamares considerados, nem mesmo na melhor das hipóteses coincidem exatamente.

Pode-se dar que uma região administrativa ou política (um estado em um país, por exemplo) tenha se constituído levando-se em consideração os obstáculos físicos oferecidos por montanhas e rios. No máximo teremos isto. No mais, as propostas para a divisão do espaço em regiões linguísticas, produtivas, consumistas, culturais, religiosas entre outras tantas possibilidades - sempre oferecerão um jogo de espaços superpostos cujos contornos não coincidem. A divisão do espaço em regiões - necessária tanto à política como à ciência, e mesmo ao senso comum - é incontornavelmente uma construção: subterfúgio, esforço ou espontaneidade da mente.

Isso não impede, é claro, que uma construção espacial - seja esta política ou científica - interfira em outras, produzindo novas complexidades. Assim, quando o jogo de decisões políticas conduz a uma certa divisão do espaço nacional em unidades federativas, produzindo fronteiras que definem naturalidades (pertenças por nascimento 
a esta ou àquela unidade federativa), pode se dar que a partir daí se criem novos delineamentos culturais. A delimitação política do espaço pode produzir uma cultura (e, por tanto, contribuir para que se incorporem à região certas características culturais). E aspectos culturais - como a língua falada em certo lugar - pode servir como elemento de pressão para novos delineamentos políticos.

De todo modo, isso pode acontecer ou não. Uma população pode resistir culturalmente ao delineamento político que lhe foi imposto, e a vontade política pode resistir às pressões culturais. Vale lembrar que o mundo humano e o mundo natural também se interferem mutuamente de muitas maneiras. Certa política de ocupação do espaço, ou determinadas práticas econômicas, podem ocasionar desmatamentos, desertificação, mudanças climáticas, de modo que uma região produzida por demandas políticas pode, em longo prazo, implicar mudanças nos aspectos naturais. Com o tempo, as gerações seguintes podem mesmo esquecer que o ambiente no qual residem apresenta aspectos naturais que foram produzidos pela ação humana, política ou economicamente.

\section{A Região diante de um problema específico}

Conforme vimos até aqui, a constituição de determinada porção do espaço como "região" envolve um certo conjunto de decisões (ou mesmo de arbitrariedades, em alguns casos) que se referem a certas escolhas. Em primeiro lugar, a Totalidade considerada (a região como pedaço do mundo, do país, ou de algum outro tipo de espaço). Em segundo lugar, o âmbito de estudos ou de ações práticas que define a proposta de divisão do espaço em curso: Economia, Cultura, Política, Educação, espacialidade física, administração pública, e assim por diante. Em terceiro lugar, o problema a ser estudado - no caso de pretendermos definir uma região a ser operacionalizada para estudo científico - ou o problema a ser enfrentado (administração estatal, saúde pública. etc).

Vamos discutir agora um quarto aspecto que deve entrar em consideração na delimitação de uma região ou de uma área (conceito vizinho, às vezes empregado como alternativa ao conceito de região). Conforme veremos, certas perspectivas teóricas ou metodológicas também podem interferir na escolha do contorno e da extensão da região a ser definida (e isso ocorre frequentemente). Quero trazer um exemplo bem concreto da Geografia, e a partir daí poderão ser pensados outros. 
Em 1946, um médico-geógrafo natural de Recife, chamado Josué de Castro (19081973), publicou um livro que se tornaria um marco para a Geografia, Política, Economia, Demografia, Saúde Pública e ciências da Nutrição. Geografia da Fome (1946) foi o título desta obra que, pioneira, decidira enfrentar a tarefa de geograficizar a fome no Brasil. A Fome, flagelo cujo destaque se reforçara ao final do segundo conflito mundial, aparece nesta obra como um problema a ser espacializado, para daí se possibilitar o seu enfrentamento político ao invés de se deixar que a fome seja "naturalizada" como um dado incômodo que decorre meramente das estatísticas populacionais.

Algumas perguntas mostravam-se incisivas. Como era (e fora) a Fome distribuída sobre o território nacional, nos períodos mais recentes e em momentos históricos um pouco mais recuados? Antes disso, o que é, mais propriamente, a Fome? Quais são as modalidades de fome ameaçam a humanidade? Que relações se estabelecem entre a Fome e o seu oposto - a Nutrição - e como para este par dialético contribuem o próprio ciclo de vida e o ecossistema, integrados a uma civilização e a uma economia que se apoiam visivelmente em uma enorme desigualdade social, ainda muito longe de ser resolvida ou mesmo minimizada pelos seres humanos? Como se relaciona a Fome com sua companheira inevitável, a Doença, e com o abismo do qual ela se avizinha, a Morte?

A começar pelo estudo mais sistemático do potencial nutritivo do solo em que vinham vivendo os seres humanos em cada região do país, e no qual cresce a natureza vegetal abrindo possibilidades para a vida animal, Josué de Castro criou seu método. $\mathrm{O}$ exame geograficizado e historicizado da pobreza ou da riqueza da terra e do seu entorno ecológico, em confronto dialético com o alarmante empobrecimento coletivo e enriquecimento de uns poucos indivíduos proporcionados pelos diversos sistemas econômicos, constituiria a base para esta inovadora análise da espacialidade da fome. Esta extraordinária obra mereceria uma leitura e estudo à parte, mas este não será o nosso objetivo aqui.

Apenas a tomamos como exemplo para verificar como Josué de Castro delimita e define as suas regiões, ou, mais propriamente, as "áreas da fome" que ele identifica no território brasileiro. Quero apenas discutir, nesse momento, como um tipo de delineamento e de abordagem do espaço deve interagir com as escolhas conceituais, com as decisões metodológicas e com o problema em estudo. Meu interesse é mostrar que a teoria e o método, bem como certas decisões técnicas de análise, também adentram a 
combinação de fatores que proporcionam o estabelecimento de um recorte científico do espaço, de um conjunto de áreas a serem problematizadas.

Em primeiro lugar, tudo parte dos conceitos. Não é possível simplesmente delimitar um espaço, ou se apropriar de uma concepção já existente de espaço com vistas a determinado estudo ou prática social, se não estabelecemos antes, com seriedade e coerência, os nossos conceitos. O principal conceito imposto pelo problema que foi enfrentado pelo geógrafo Josué de Castro não podia deixar de ser o da própria "fome". Como médico e nutricionista que era - além de ser um notável geógrafo que incluía em seu acorde interdisciplinar a atuação política dirigida contra a fome e a miséria - Josué de Castro se orientou por uma definição de fome apoiada na biologia e na fisiologia humana.

Existiriam dois tipos fundamentais de fome: a subnutrição, que é a fome provocada por carências alimentares (níveis inadequados de assimilação de vitaminas, sais minerais e proteínas) e a inanição, estado que se avizinha da morte em decorrência da ausência prolongada de alimentos. A primeira, embora não receba tanta visibilidade quanto à segunda, seria igualmente perniciosa nas suas formas mais intensas, pois destrói a vida por dentro da própria vida, lentamente, levando a doenças e a um silencioso morrer cotidiano. A subnutrição radical pode ocasionar, de resto, problemas coletivos como o do raquitismo, entre outros. Josué de Castro destaca a importância de os seres humanos se conscientizarem a respeito desta modalidade de fome à qual chega a se referir como a "fome oculta":

"[Eis aqui] a fome parcial, a chamada fome oculta, na qual, por falta permanente de determinados elementos nutritivos em seus regimes habituais, grupos inteiros de população se deixam morrer lentamente de fome, apesar de comerem todos os dias" (CASTRO, 1992, p.37).

Além de perceber na Fome estas duas fomes - a subnutrição e a inanição - Josué de Castro também as situa em uma perspectiva de diferentes escalas. Conceitualmente, a Fome também deveria ser percebida em três alternativas, conforme a escala de espraiamento. Há a fome coletiva - quando a subnutrição ou a inanição se generaliza em uma espacialidade mais ampla e atinge um conjunto bem maior da população. Há a fome local, que se restringe a uma área bem menor, e que pode ocorrer, inclusive, sob a forma 
de bolsões no interior de áreas mais amplas, não classificáveis propriamente como áreas de fome. Pode-se pensar ainda na fome individual, quando nos referimos ao indivíduo que morre de fome no interior de suas circunstâncias e de sua trágica trajetória individual, destacada da experiência coletiva.

Definido o conceito, chegamos ao ponto que nos interessa. Como se tratava de espacializar a fome, de percebê-la no interior e na extensão de um território nacional, cumpria agora definir as “áreas de fome". Josué de Castro tomou como base para partição de espaço uma divisão apenas inicial em regiões que, em suas linhas mais gerais, já existia na época. Seu mapa das regiões alimentares (e da fome) aproveita um pouco uma divisão política do território brasileiro que já vinha sendo proposta desde 1938 pelo IBGE, recortando o país em cinco regiões. Além disso, Josué de Castro incorpora alterações que o próprio IBGE acabara de propor em 1945. De qualquer modo, o autor estabeleceu nas linhas de contorno algumas adaptações, com vistas ao seu problema específico de estudo.

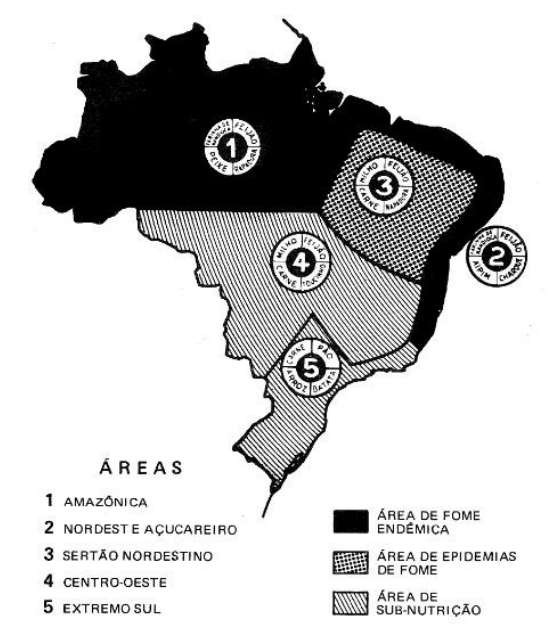

Mapa das 'áreas de fome', proposto por Josué de Castro e incluído no prefácio de 1960 para Geografia da Fome

Destaca-se a separação do Nordeste em dois. As 'áreas de fome' seriam a Amazônia, o Nordeste Açucareiro, o Sertão Nordestino, o Centro-Oeste e o Sul. Fome, mesmo, estaria nas três primeiras áreas, conforme veremos logo adiante. É importante notar que é a atenção aos tipos de solo e de vegetação - cruciais para o problema examinado - que levam o autor a acatar inicialmente uma divisão geográfica já existente, mas empreendendo algumas adaptações importantes. O essencial, contudo, é a sua definição mais precisa de "área de fome", a qual se agrega ao mapa proposto. Seria uma 
área de fome aquela na qual pelo menos metade da população sofre de subnutrição e/ou inanição.

O conceito de área de fome, visto sob o ponto de vista da aferição do contingente demográfico que é afetado pela fome coletiva, é um aspecto essencial do modelo de Geografia da Fome proposto por Josué de Castro. Além disso, o delineamento de uma área de fome também deveria ser visto sob a perspectiva do tempo no qual perdura o flagelo da subnutrição ou da inanição. Se na população localizada há uma permanência, uma continuidade do estado de subnutrição que parece se eternizar, tem-se a "fome endêmica". Se a fome coletiva é provisória, mesmo que mais terrível, tem-se uma "fome epidêmica".

Estas notas conceituais - endemia e epidemia - vinham do vocabulário médico já utilizado para as doenças que se espraiam por uma população. No estudo de Josué de Castro, aliás, Fome e Doença andam juntas. Uma gera a outra. Um dos objetivos da pesquisa, inclusive, é correlacionar os tipos de doenças que surgem, em cada uma das áreas de fome, em decorrência da especificidade das carências alimentares que as afeta.

Neste ponto, a conceituação assume um novo nível de aprimoramento. Em cada uma das áreas de fome, o contorno local da subnutrição é gerado por uma configuração singular de doenças, a qual se dá em decorrência da junção do sistema social de desigualdade em vigor com o ambiente natural específico de cada área - considerando que em cada uma das regiões a combinação de solo e natureza impõe, para a população menos favorecida, certas carências de vitaminas, sais minerais ou proteínas. Não posso me estender nesta importante parte do estudo, pois nos distanciaríamos muito do nosso propósito, que é apenas o de compreender como Josué de Castro lidou com o espaço e com a divisão do espaço para este problema específico que configura uma Geografia da Fome.

Distinguimos atrás a "fome endêmica" e a "fome epidêmica" - definíveis respectivamente como aquela que apresenta uma longa duração, tornando-se constante e aparentemente permanente, e aquela que apresenta uma duração mais curta (um surto de fome, por exemplo, ocasionado por certas circunstâncias). Na África, existem certas regiões nas quais a fome - na sua forma "inanição" - tornou-se endêmica. Nos países assolados pela guerra, ou atingidos por alguma catástrofe natural, pode ocorrer uma fome epidêmica, que depois será debelada, e que talvez nunca mais retorne. 
Todavia, existe a situação singular das 'fomes epidêmicas' que são 'cíclicas'. Conhecemos, no Brasil, o problema das secas no Sertão Nordestino, que retornam ciclicamente levando muitos habitantes a se transformarem em retirantes. É impressionante o contraste entre os momentos de seca e o razoável afloramento vegetal dos momentos em que ela não está presente. O compositor pernambucano Luís Gonzaga (1912-1989) imortalizou este contraste na famosa canção Asa Branca (1947).

Já que falamos em seca nordestina, podemos lembrar que um problema como este - de proporções sociais alarmantes - também pode demandar a delimitação de uma área ou região específica com vistas a uma racionalização que almeje enfrentar a questão. Por isso, o governo federal definiu em 1951 uma área que passou a ser chamada de "Polígono da Seca", e que abarca pedaços de quase todos os estados do Nordeste (a exceção é o Maranhão) e também o norte de Minas Gerais. Trata-se como uma região (ou área) o Polígono da Seca - uma delimitação operacional para o enfrentamento desta questão social, bem como para a formulação de políticas e estratégias com vistas a combater os males ocasionados pela recorrência cíclica da prolongada ausência de chuvas. Conforme se vê, cada problema a ser enfrentado ou estudado convida à formulação de novas divisões do espaço. Entrementes, voltemos à argumentação anterior.

Tendo terminado de forma muito simplificada esta modesta apresentação da obra Geografia da Fome, quero retornar agora à definição de 'área de fome'. Josué de Castro define como áreas de fome aquelas em que pelo menos metade da população sofre a fome em alguma de suas modalidades (subnutrição ou inanição). Por que a metade? Este ponto nos coloca diante das escolhas metodológicas que devem ser feitas pelo pesquisador. Este precisa organizar a sua realidade examinada. É preciso oferecer uma imagem do problema. Um mapa, um limiar numérico, são recursos interessantes em uma argumentação e na exposição didática ou científica de um problema. Metade de uma população sofrendo de fome, de fato, é um número que impressiona. Dez por cento, não impressiona muito a maioria das pessoas, ou impressiona menos.

Pode ocorrer, contudo, que daqui a anos - em um mundo que tenha avançado mais no combate à Fome e nos procedimentos para a sua minimização - estes dez por cento tenham se tornado então um limiar mais agressivo. Os números são relativos. Históricos. Hoje, por exemplo, uma cidade de cerca de trinta mil habitantes é vista como uma pequena cidade, ou ao menos como uma cidade média. Na Idade Média, seria vista como 
uma cidade enorme. De igual maneira, se era preciso 50\% de Fome para impressionar as pessoas nos anos 40, hoje este limiar talvez tenha se reduzido, e no futuro pode se reduzir ainda mais (é uma esperança). Uma nova Geografia da Fome, escrita em momentos distintos, redefiniria por certo o limiar de população faminta que é utilizado na definição de área de fome.

É o que dizíamos quando foi ressaltado que também as escolhas teóricas e metodológicas adentram a configuração de aspectos que incidem sobre o delineamento das regiões ou áreas. As escolhas do pesquisador também são demandas da sociedade na qual ele vive. Subdividir o espaço é uma operação que deve levar muitas coisas em consideração, em particular nos estudos científicos. As regiões não estão dadas previamente. Podemos produzir uma proposta nova de subdivisão do espaço, ou podemos adotar um modelo de subdivisão do espaço que já existe, se este favorecer nosso problema em estudo.

O problema, aliás, deve interferir tanto no contorno externo da região a ser constituída pelo pesquisador, como nos seus contornos internos, isto é, na sua divisão ou não em subáreas a serem consideradas, assim como nos desenhos destas últimas. Josué de Castro dá-nos um exemplo disso no quarto capítulo de Geografia da Fome (CASTRO, 1992, p.175-263), em sua análise do Sertão Nordestino - uma das três áreas de fome efetivas, e particularmente a que tem a característica singular de ser uma área epidêmica de fome em decorrência das secas cíclicas.

Ainda no princípio do capítulo, o autor discrimina, no interior da região mais ampla do Sertão Nordestino, três subáreas mais específicas - Agreste, Caatinga e "Alto Sertão". Tal subdivisão interna, já tradicional, constitui o procedimento correto para o estudo desta região, de modo mais geral. O Agreste, área intermediária entre o litoral e a Caatinga, e o "Alto Sertão", área intermédia entre a Caatinga e a região Amazônica, possuem nuances próprias, do ponto de vista do clima e da vegetação. No entanto, conforme ressalta o autor, para o problema em estudo - uma Geografia da Fome, com a concomitante identificação das áreas alimentares - as três áreas compõem uma unidade mais geral. O problema demanda tratá-las em conjunto, desprezando as nuances internas:

Embora nas características de seu revestimento vivo, e mesmo em certos aspectos de sua geografia econômica, cada uma destas subáreas apresente traços que lhe dão individualidade e impõem, num estudo de geografia humana, uma análise particularizada, para o nosso objetivo, 
de um ensaio de geografia alimentar da região, é perfeitamente dispensável a caracterização detalhada de cada uma delas, desde que em todo o regime alimentar mantém a mesma unidade de hábitos e de composição, com pequenas nuances locais, variações de amplitudes semelhantes às de quaisquer outras áreas alimentares de certa extensão Sob o ponto de vista alimentar, podemos agrupar as três subáreas numa só: a área do milho do sertão nordestino. (CASTRO, 1992, p.180).

O problema examinado, portanto, com suas demandas teóricas e metodológicas, é o que deve conduzir não apenas ao delineamento da extensão e dos contornos de uma área ou região, como também aos critérios que a definem, bem como, por fim, à necessidade (ou não) de se subdividir a área internamente. A área, ou a região, não é um dado prévio. Se o pesquisador apropria-se de alguma divisão do espaço já existente - uma subdivisão político-administrativa das regiões, ou um recorte geográfico tradicional e já mais conhecido - deve empreender os ajustes necessários. As escolhas, enfim, procedem do problema examinado, do âmbito de estudos no qual se insere a análise, das opções teóricas e metodológicas, da escala de observação empregada. A região, veremos oportunamente, nem sempre é aquilo do que se parte, mas também aquilo ao qual se chega.

Sobre a atualidade possível de Geografia da Fome, suas análises pertinentes às raízes históricas do problema geográfico da fome no Brasil são ainda adequadas, desde que se observe que o quadro exposto tem suas balizas históricas bem definidas. No Brasil e no mundo, a dependência dos regimes alimentares em relação ao tipo de produção local constituiu uma permanência até fins do período industrial. A partir dos anos 1990, com prenúncios desde os anos 1970, praticamente entramos em uma nova era (muitos a chamam de pós-industrial ou de sociedade global). Há mudanças importantes na antiga relação entre solo, agricultura e alimentação.

Para além da própria globalização - a qual dá a tônica do novo período destacam-se notáveis desenvolvimentos na rapidez e eficiência dos meios de transportes aéreos, terrestres e navais. Tornou-se possível transportar, por exemplo, extraordinárias quantidades de carne e cereais em verdadeiros "navios frigoríficos", unindo pontos distanciados do planeta (SANTOS, 2014-b, p.42). O mesmo ocorre com relação a toda uma diversidade de produtos que, nos dias de hoje, pode chegar com muito maior facilidade e segurança ao sistema alimentar de cada país. 
Assim, cada vez mais o milenar problema da fome e da subnutrição deixa de ser uma incontornável conseqüência da produção local, para se reafirmar como uma ainda não resolvida questão social (e internacional) de distribuição da renda, além de se mostrar como uma questão de educação alimentar. A subnutrição, nesse mundo de variadas ofertas, pode ocorrer contraditoriamente também em estratos sociais mais favorecidos, pois um indivíduo pode sofrer de subnutrição por ignorância nas suas escolhas alimentares.

Distribuir não só a renda, mas também a informação, é por isso questão de primeiro plano. De todo modo, a mono-especialização da produção agrícola, em algumas localidades, não mais necessariamente implica lacunas nutricionais para a população do lugar. Ao lado disso, artifícios tecnológicos vários - apoiados na tríade da química, genética e mecanização - incrementaram cada vez mais a possibilidade de introduzir espécies vegetais e animais de um lugar original em outros que antes lhes seriam estranhos. O homem, por fim, pode agora impor, aos mais renitentes solos, novas potencialidades agrícolas. O que soa estranho, nesta nova era com tantas possibilidades, é que ainda haja tanta fome no mundo. Posto isso, retornemos a mais algumas considerações relativas aos problemas geográficos de divisão do espaço.

\section{Áreas e zonas: outros divisores do Espaço}

O vocabulário da divisão espacial inclui mais alguns termos, de modo que será oportuno discutir eventuais distinções em torno dos conceitos de "região", "área" e “zona”, entre outros conceitos divisores do espaço. Área e região são conceitos vizinhos, e em alguns casos empregados de maneira sinônima. Na obra que acabamos de examinar, Josué de Castro bem que poderia ter falado, ao invés de em "áreas de fome", nas "regiões de fome". Em algumas situações as noções de "área" e "região" são, de fato, intercambiáveis. Em seu uso mais tradicional, o qual não é necessariamente e nem sempre o mais adequado, as regiões podem se referir a um quebra-cabeça no qual certa totalidade (mundo, país, estado, cidade) é seccionada em diferentes porções do espaço que se ajustam mutuamente, encaixando seus contornos umas nas outras (tal como nos quebracabeças). 
As regiões impostas pela política e administração pública tendem a este modelo. Assim, nos dias de hoje essa totalidade que é o Brasil encontra-se oficialmente dividida em 5 regiões: norte, nordeste, centro-oeste, sudeste, sul. Cada uma delas contém alguns dos estados brasileiros. Neste modelo de divisão regional, nada fica de fora ou nada sobra.

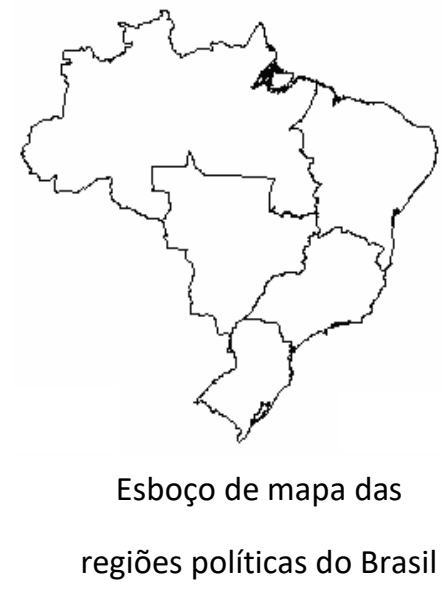

No bem ajustado quebra-cabeça político-administrativo das regiões tudo pode se encaixar, e a totalidade é rigorosamente preenchida conforme um plano que dá conta de toda a espacialidade envolvida. Alguns temas geográficos também se adequam ao modelo do quebra-cabeça regional. Assim, é possível seccionar o planeta ou o país em certo número de regiões geológicas, ou seccionar esta mesma totalidade em conjuntos vários de regiões climáticas, biológicas, hidrográficas, entre outras. Estas diversas possibilidades de divisões em regiões de uma mesma totalidade, como o Brasil, não precisam se superpor obviamente nos seus contornos internos.

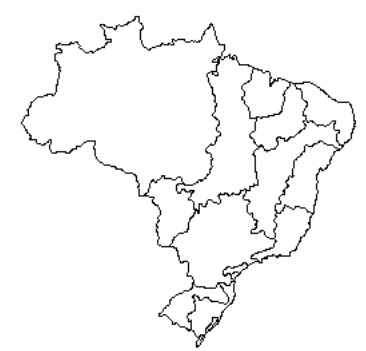

Esboço de mapa das regiões hidrográficas do Brasil 
Deste modo, o aspecto construtivo das partilhas regionais pode ser vislumbrado desde o mais superficial exame dos mapas escolares que encaminham representações cartográficas do Brasil. Por outro lado, conforme veremos mais adiante, diversos temas de estudo autorizam o delineamento de uma região em torno de um problema específico, que não coincidirá necessariamente com as regiões impostas pelos poderes políticos ou pelos grandes patamares temáticos da Geografia. A isto, todavia, voltaremos no segundo capítulo deste livro. Enquanto o delineamento de regiões pode oscilar, conforme o campo de aplicação, entre o modelo dos quebra-cabeças regionais e o da região definida por problemas específicos, a "área” tende a se mostrar como um recorte qualquer no espaço, o qual não precisa se encaixar necessariamente em um quebra-cabeça com outras áreas.

Por isso, disse atrás que as "áreas de fome" postuladas por Josué de Castro bem que poderiam ter sido chamadas de "regiões de fome", sem prejuízo da compreensão ou sem inadequação na escolha desta categoria de análise. Já o chamado "polígono da seca", embora seja por vezes referido como região (a região do polígono da seca), poderia ser também categorizado como uma "área". Fez-se um recorte isolado no interior desta totalidade, o Brasil, configurando-se a porção do espaço nacional que sofre o flagelo da seca ou as agruras de um determinado tipo de clima. Não existe, todavia, um quebracabeça a ser preenchido com outras áreas análogas (o polígono das chuvas torrenciais, o polígono das chuvas moderadas). A área justifica-se por si mesma.

O Polígono da Seca é um recorte singular e único no território nacional, operado em função de um problema específico. De acordo com este viés, pode ser tratado como uma área. As áreas podem se superpor a outras áreas, relativas a problemas distintos. Além disso, não têm, necessariamente, um compromisso de se complementar. Já as regiões, na sua vertente de tratamento mais convencional, costumam compor um mosaico de encaixes, cujos contornos se ajustam e fazem fronteiras. Na História, este modelo pode ou não ser o mais indicado, conforme veremos oportunamente.

A dissolução de algumas áreas em momentos específicos, bem como seus contornos menos bem definidos, contrasta com a tendência mais rigorosa na delimitação das regiões. Quando uma epidemia ocorre, ou um vazamento nuclear, pode-se falar em uma área de contaminação que perdurará em sintonia com o fenômeno que representa (a área liga-se a um tempo). Se há deslizamento de terra, correntes marítimas de maior 
repuxo no litoral, ou tubarões que o rondam em certa temporada, pode-se falar nas "áreas de risco". O mapa da criminalidade, e outros, podem se valer da mesma conceituação.

Dos meteorologistas, espera-se que, diante dos furacões, tornados e tempestades tropicais que estão prestes a se formar, sejam capazes de traçar as áreas nas quais se dará o seu percurso. Bem entendido, a área pode se formar dentro de uma região. Assim, o Sertão é a região ou sub-região do nordeste na qual se formam ciclicamente áreas de seca. A Seca pode atingir esta região em diferentes escalas, formando áreas de distintas grandezas. Secas parciais podem atingir e se restringir a localidades. Todavia, diversas secas atingiram áreas bem mais extensas. Em 1915, uma destas grandes secas espraiouse por uma área que praticamente coincidiu com o estado do Ceará, e em 1932 a Seca abarcou toda a região semiárida, recobrindo a área do Polígono da Seca.

Tendo em vista a maior flexibilidade de seus contornos no espaço e no tempo, o conceito de área adquire uma potencialidade que nem sempre encontramos em certos usos do conceito de região. Se a região é o recorte que se estabelece no espaço, por outro lado a área, em algumas situações, pode ser vista como o "campo" que se estende sobre o espaço, em um sentido mais imaterial. Campo, aqui, não se refere só ao "espaço porção de terra", mas também ao campo de forças (espaço no qual se configura uma relação de forças, "espaço-energia”).

Por isso, para aspectos relativos à cultura, o conceito de área, em sua ligação com a ideia de campo, agrega novas possibilidades. Fala-se, por exemplo, nas "áreas de influência" para ressaltar a conexão entre um espaço ou outro que age sobre ele através das transferências culturais, das heranças simbólicas, das ligações políticas. Um pouco por causa desta maior abstração do conceito de área, o qual tem a sua origem nas operações matemáticas e geométricas, as áreas também podem se referir ao espaço imaterial (o espaço do saber, por exemplo). Não é de se estranhar que tenhamos "áreas de conhecimento" (campos de saber).

Um terceiro conceito divisor do espaço é o de "zona". Mais flexível, trata-se de uma noção que ora se avizinha do conceito de região, ora se aproxima da ideia que podemos fazer de uma área. Temos o primeiro caso - as zonas como subdivisões de uma região em sub-regiões - em algumas grandes cidades. A cidade do Rio de Janeiro, por exemplo, é dividida pela administração pública e pelo imaginário cotidiano em Zona Norte, Zona Sul, Zona Oeste e Centro. Rigorosamente falando, temos aqui as quatro 
macrorregiões da cidade. Com as quatro zonas, em perfeito encaixe e com as fronteiras bem definidas de umas em relação às outras, abarca-se toda a espacialidade urbana sem deixar sobras. Em um nível escalar de maior amplitude - o do planeta - a noção de “zonas" também tem sido empregada em aproximação a "regiões". Do pólo norte ao sul, as cinco zonas climáticas da terra cortam de alto a baixo a esfera planetária, como sessões horizontais.

Não obstante, por vezes a noção de "zona" aproxima-se mais do conceito de "área". Ainda dentro da espacialidade urbana, podemos falar na "zona do meretrício". Temos aqui um recorte no espaço urbano, definido por certa prática. É uma área permanente, embora clandestina. Tem-se também, nas cidades costeiras, a zona portuária - uma área naval e ligada ao comércio marítimo. Por outro lado, a noção de zona também pode se referir a áreas não permanentes: a zona de contaminação, ou as zonas de conflito (praticamente sinônimos de "área de contaminação" e "área de conflito").

Por fim, a noção mais flexível de zona pode ser utilizada para amplitudes maiores. Aqui, uma zona pode recobrir seções transversais de regiões diversas. A Zona da Mata, à altura da chegada dos portugueses nas terras que mais tarde conformariam o Brasil, era uma extensa faixa de floresta entre a margem litoral e as áreas interiores, às vezes limitada pelas montanhas, e que atravessava de alto a baixo o litoral do Nordeste, adentrando depois o que mais tarde seria a região sudeste.

\section{Território: o Espaço e o Poder}

Abordemos um penúltimo conceito relevante: o de Território. Devo evocar aqui outro geógrafo bem importante para a discussão do espaço, embora ainda pouco conhecido pelos historiadores. É Claude Raffestin (n.1936), que faz uma distinção bastante interessante entre o "espaço" e o "território". Segundo Raffestin (RAFFESTIN, 1993, p.143), "o território se forma a partir do espaço, é o resultado de uma ação conduzida por um ator sintagmático (ator que realiza um programa) em qualquer nível. Ao se apropriar de um espaço, concreta ou abstratamente (seja através da ocupação, seja através da representação), o ator 'territorializa' o espaço". 
Pode-se observar que a definição de "espaço" proposta por Raffestin, a princípio necessariamente ligada à materialidade física, deixa de fora as possibilidades de se falar em outras modalidades de espaço - o espaço social, o espaço imaginário, o espaço virtual - as quais se constituem no próprio momento da ação humana. De qualquer modo, o sistema conceitual proposto por Raffestin é importante porque chama atenção para o fato de que a territorialização do espaço ocorre não apenas com as práticas que se estabelecem na realidade vivida, como também com as ações que são empreendidas pelo sujeito de conhecimento:

'Local' de possibilidades, [o espaço] é a realidade material preexistente a qualquer conhecimento e qualquer prática dos quais será o objeto a partir do momento em que um ator manifeste a intenção de dele se apoderar. Evidentemente, o território se apoia no espaço, mas não é o espaço. É uma produção, a partir do espaço. Ora, a produção, por causa de todas as relações que envolve, inscreve-se num campo de poder. Produzir uma representação do espaço já é uma apropriação, uma empresa, um controle portanto, mesmo se isso permanece nos limites de um conhecimento. (RAFFESTIN, 1993, p.144).

É oportuno lembrar que a consciência de uma territorialidade que é transferida ao espaço pode transcender o mundo humano. Também os animais de várias espécies, que não apenas o homem, costumam territorializar o espaço com as suas ações e com gestos que passam a delinear uma nova representação do espaço. O lobo que "marca o seu território" cria para si (e pretende impor a outros de sua espécie) uma representação do espaço que o redefine como extensão de terra sob o seu controle. Demarcar o território é demarcar um espaço de poder. No âmbito da macropolítico, é isto o que fazem os estadosnações ao constituir e estabelecer um rigoroso controle sobre suas fronteiras. Entrementes, a noção de território pode ser levada adiante.

O geógrafo francês Yves Lacoste (1976), em uma abordagem que foi denominada "espacialidade diferencial", propõe a possibilidade de se pensar não em enquadramentos espaciais, mas sim em "espacialidades superpostas" (espaços que se superpõem sem que seus contornos coincidam, gerando situações geográficas de grande complexidade). A combinação desta perspectiva com os conceitos de espaço e território propostos por Claude Raffestin também permitiria falar mais propriamente de 'territorialidades superpostas'. 
Em sua realidade vivida, os seres humanos estão constantemente se apropriando do espaço sobre o qual vivem e no qual estabelecem suas variadas atividades e relações sociais. Um mesmo homem, no seu agir cotidiano e na sua correlação com outros homens, vai produzindo territórios que apresentam maior ou menor durabilidade. Ao se apropriar de determinado espaço e transformá-lo em sua propriedade - seja através de um gesto de posse ou de um ato de compra em um sistema onde as propriedades já estão constituídas - um sujeito humano define ou redefine um território. Ao se estabelecer um certo sistema de plantio sobre uma superfície natural, ocorre aí nova territorialização do espaço, caracterizada por uma nova paisagem produzida culturalmente e por uma produção que implicará em controle e conferirá poder.

O território que se produz e se converte em propriedade fundiária - ou em unidade política estável para considerar um nível mais amplo - pode existir em uma duração bastante longa antes de ser tragado por um novo processo de reterritorialização. Contudo, se um homem exerce a profissão de professor, ou de político, no momento de exercício destas funções poderá estar territorializando uma sala de aula ou um palanque por ocasião de um comício, constituindo-se estes em territórios de curta duração. A vida é devir de territórios de longa e curta duração, que se superpõem e se entretecem ao sabor das relações sociais, das práticas e representações. Sob certo ângulo, a História Política é o estudo deste devir de territorialidades que se constituem a partir dos espaços físicos, mas também dos espaços sociais, culturais e imaginários.

Com relação à associação entre território e espaço, deve-se notar que, embora habitualmente pensemos no território como um poder ancorado em uma porção de espaço, nada impede que a territorialização afete simultaneamente porções não contíguas do espaço. Milton Santos já observava que "o território, hoje, pode ser formado por lugares contíguos ou por lugares em rede" (SANTOS, 2014, p.139). Mesmo na Idade Média existiam territórios estabelecidos em um conjunto de porções não-contíguas do espaço, como atestam os feudos formados por glebas separadas umas das outras, sem continuidade, e que podiam constituir com outros feudos um curioso retalho formado por diferentes senhorios. A simultânea libertação do olhar geográfico e historiográfico em relação aos antigos modos de abordar o espaço é uma conquista destas duas ciências.

Os caminhos recentes da Geografia Humana convergiram para considerar o espaço como “campo de forças". É a um espaço social, conforme vimos atrás, que Milton 
Santos (SANTOS, 1978, p.174) se refere quando propõe associar a noção de campo a uma Geografia Nova. Abordando a questão do ponto de vista do Materialismo Dialético, ele chama atenção para o fato de que o espaço humano é, em qualquer período histórico, resultado de uma produção. "O ato de produzir é igualmente o ato de produzir espaço". O homem, que devido à sua materialidade física é ele mesmo espaço preenchido com o próprio corpo, além de ser espaço também está no espaço e produz espaço.

\section{REFERÊNCIAS}

BOURDIEU, Pierre. “A Ideia de Região” In: O Poder Simbólico. São Paulo: Difel, 1989. p.107-132.

CASTRO, Antônio B. de. Sete Ensaios sobre a Economia Brasileira, I. Rio de Janeiro: Forense, 1980.

CASTRO, Josué de. A Alimentação Brasileira à luz da Geografia Humana. Rio de Janeiro: Livraria do Globo, 1937.

CASTRO, Josué de. Geografia da Fome. Rio de Janeiro: Griphus, 1992 [orig.: 1946] [Prefácio: 1960].

FOUCAULT, Michel. A Ordem do Discurso. São Paulo: Edições Loyola, 1996.

LA BLACHE, P. Vidal de. "La Géographie Politique, a propôs dês Écrits de M. Frédéric Ratzel. Annales de Géographie, n³2. Année 7, p.97-111, 1898.

LACOSTE, Yves. Geografia: isto serve, antes de mais nada, para fazer a Guerra Campinas: Papirus, 1988 [original: 1976].

RAFFESTIN, Claude. Por uma Geografia do Poder. São Paulo: Ática, 1993 [original: 1980].

CASTRO, Josué de. A Geopolítica da Fome. Rio de Janeiro: Livraria do Globo, 1951.

SANTOS, Milton. Por uma Geografia Nova - da crítica da geografia a uma geografia crítica. São Paulo: EDUSP, 2002-b [original: 1978].

SANTOS, Milton. Espaço e Método. São Paulo: EDUSP, 2008 [original: 1985].

SANTOS, Milton. Técnica, Espaço, Tempo. São Paulo: EDUSP, 2013 [original: 1994]. 

tempos de pensamentos anticientíficos

SANTOS, Milton. Metamorfoses do Espaço Habitado. São Paulo: EUSP, 2014-b [original: 1988].

SANTOS, Milton e SILVEIRA, Maria Laura. O Brasil - território e sociedade no início do século XX. Rio de Janeiro: Record, 2003. 